years old, and every fifth (19.6) was from 61 to 70 years old. The overwhelming majority $(61.1 \%)$ learned about the training from employees' announcements or on the website of a medical organization. Interestingly, almost a third of the participants (31.9\%) listened to the lecture to "prevent problems in the future" or "for general development," the rest either get sick themselves or have relatives with these problems. The significance and usefulness of the school on a scale from 0 to 10 points was assessed by $75 \%$ participants at 10 points, another $21 \%$ from 7 to 9 points, and for 1 participant - by 3 and 4 points. When answering the question: "Will something change in the understanding of your disease or further managing after today's lesson?" most of the listeners answered that "they are planning to change their lifestyle" (55.4\%), a little less - "understands that you need to come to an in-person appointment" $(27.4 \%)$, "listened due to problems with relatives" $(30.4 \%)$ and "understands that it is necessary to adjust the treatment" $(23.2 \%) .87 .5 \%$ of the responders rated the degree of interest with which the teacher led the school at 10 points; all $100 \%$ of participants expressed a desire to attend the following events. When comparing the school with television programs or other similar events, $83.9 \%$ of people noted a higher level of information importance and $87.5 \%$ of accessibility of its presentation. All responders with a high probability were ready to recommend schools to another people ( $85.7 \%$ for 10 points), trust the doctor conducting such schools (94.6\% for 10 points) and would turn to this doctor if possible ( $87.5 \%$ for 10 points). Also, all participants actively answered the question about the desired topic of future schools.

Conclusion: the conducted evaluation of the online format of schools for patients with rheumatic diseases or complaints has confirmed the high satisfaction of patients with this form of communication, the presence of a certain "request" for such format, clarity and accessibility of the transmitted information. The most important result of the training can be considered the readiness of patients to change their lifestyle and the understanding that it is necessary to observe or consult a doctor.

Disclosure of Interests: None declared

DOI: 10.1136/annrheumdis-2021-eular.3046

\section{AB0852 BREAKING THE GLASS CEILING IN MEXICAN RHEUMATOLOGY}

I. J. Colunga-Pedraza ${ }^{1}$, G. Serna-Peña ${ }^{1}$, D. Alpizar-Rodriguez ${ }^{2}$, N. GuajardoJauregui ${ }^{1}$, R. Galarza-Molina ${ }^{3}$, D. Á. Galarza-Delgado ${ }^{1}$, C. F. Pacheco Tena ${ }^{2}$, M. A. Reyes Soto ${ }^{1}{ }^{1}$ Hospital Universitario "Dr. José Eleuterio González", Universidad Autónoma de Nuevo León, Rheumatology, Monterrey, Mexico; ${ }^{2}$ Colegio Mexicano de Reumatología, Rheumatology, Ciudad de México, Mexico; ${ }^{3}$ Universidad Auntónoma de Nuevo León, Political Science, Monterrey, Mexico

Background: The term "glass ceiling" has been used since the late eighties, to designate an invisible barrier that prevents highly qualified women from reaching positions of responsibility in the organizations they work. (1) At first, this concept was used to analyze the career of women who, having a professional career and a high level of competition in their workplaces, encountered an interference when trying to advance in their careers. (2). The so-called "glass ceiling" refers to a last barrier based on prejudice towards women that prevents them from advancing to high-level positions.

Currently, there is almost the same number of men and women affiliated to the Mexican College of Rheumatology (CMR). The position of president is the highest directorial position, we undertook the task of evaluating the percentage of women who have historically held that leadership position.

Objectives: To assess the percentage of woman who have occupied the position of president of the Mexican College of Rheumatology.

Methods: Observational, cross-sectional study. We evaluated the number of man and women who have historically held the position of president of the CMR.

Results: Currently, the CMR has 630 active members, 308 women (48.9\%) and 322 men $(51.1 \%)$. Among rheumatologists younger than 40 years of age, women represent $58 \%(n=128)$. We found that historically the CMR has had 48 presidents, of which only $4(8.3 \%)$ are women.

Conclusion: There is a big gender gap between presidents of the CMR. It is important to talk about the gender perspective and recognize the causes that have originated this gap. Incorporating the gender perspective in senior management is a pending issue for our CMR.

REFERENCES:

[1] Barberá E, Ramos A, Sarrió M, et al. Laberinto de cristal en el liderazgo de las mujeres. Psicothema 2011;23(2):173-179.

[2] Bustos O. Mujeres rompiendo el techo de cristal: el caso de las universidades. OMNIA - Revista de la Coordinación de Estudios de Posgrado 2002(41);1-7.
Acknowledgements: We have no acknowledgements to declare.

Disclosure of Interests: None declared

DOI: 10.1136/annrheumdis-2021-eular.3417

\section{Educational cases}

\section{AB0853 IGG4-RELATED DISEASE CAUSING OCULAR NERVE PALSIES AND ORBITAL APEX SYNDROME: CASE REPORT AND LITERATURE REVIEW}

F. Javed ${ }^{1}$, C. Chung ${ }^{2}$, H. Fayyaz ${ }^{1}$, R. Jeffery ${ }^{1} .{ }^{1}$ Northampton General Hospital, Department of Rheumatology, Northampton, United Kingdom; ${ }^{2}$ Northampton, Department of Ophthalmology, Northampton, United Kingdom

Background: IgG4-Related Disease (IgG4-RD) is a systemic immune-mediated fibroinflammatory condition. The epidemiology is not well defined: it usually affects adults from middle-age onwards, predominantly male. Both B and T-cells are central in IgG4-RD pathogenesis, as demonstrated by the efficacy of B-cell depletion therapy.lgG4-RD can affect multiple organs including the central and peripheral nervous system, producing a constellation of clinical symptoms and signs, depending on the organ structures involved.

IgG4-related orbital disease is relatively rare can implicate all extra-ocular muscles, structures emerging from the Orbital apex, optic canal, or superior and inferior orbital fissure. Depending on the structures involved, it can produce different or sometimes subtle clinical presentations, posing diagnostic challenge. There were case reports of IgG4-related ophthalmic disease misdiagnosed as intraocular tumour.

Objectives: IgG4-RD is increasingly recognised as an entity affecting the head and neck region. However, it rarely involves skull base and presents with orbital apex syndrome. In this current case report, we describe an interesting case of IgG-related orbital disease presenting with ocular nerve palsies and orbital apex syndrome.

Methods: Case report.

Results: A 36-year-old gentleman with cocaine and alcohol misuse presented with a 2-month history of left sided headache, diplopia, recurrent ea infections, otalgia and hearing loss. Initial imaging suggested left otomastoiditis and intravenous antibiotics were commenced. Contralateral partia third nerve palsy with pupil sparing was elicited. 2 months later, there was worsening right eye ptosis, proptosis, right relative afferent pupillary defect reduced visual acuity and colour vision as well as a near-complete ophthalmoplegia. Subsequent imaging showed worsening soft tissue swelling centred on the upper left parapharyngeal and masticator space, with multiple perineural enhancement and lateral extension to right orbital apex and orbital fissures. Blood tests only revealed raised IgG4 subclass. Infectious aetiology was excluded. Left nasal mass biopsy performed showed no fungal organism or malignancy. There were lymphoplasmacytic proliferation but no storiform fibrosis or obliterative phlebitis. IgG4 immunostaining on two assessable fields revealed 22 and 17 positive plasma cells respectively, and an IgG4: IgG ratio of $<10 \%$, and $50 \%$ in the other. Significant improvement was seen clinically and radiologically with antibiotics and a tapering regime of oral Prednisolone. Patient was commenced on Azathioprine as long term immunosuppression

Conclusion: A high degree of clinical suspicion is necessary to diagnose IgG4-RD when presenting with orbital apex syndrome and ocular nerve palsies,IgG4-RD can mimic mastoiditis of infectious aetiology. Other differentials may include cocaine-induced midline destructive lesions and granulomatosis with polyangiitis. The diagnosis can be supported by elevated serum IgG, elevated IgG index and pathognomonic histopathological findings. . The diagnosis of IgG4-related orbital disease should be deliberated on by a multidisciplinary group, with every effort being made to exclude an infectious aetiology, before embarking on immunosuppressive therapy.Primary treatment is with steroids. However, immunotherapy using azathioprine can be utilised in recurrent disease or patients with steroid intolerance.

\section{REFERENCES:}

[1] Goto H, Ueda S. Immunoglobulin G4-related ophthalmic disease involving the sclera misdiagnosed as intraocular tumor: report of one case. OculOncolPathol. 2016;2(4):285-8.

[2] Ohyama K, Koike H, lijima M, et al. IgG4-related neuropathy: a case report JAMA Neurol. 2013;70(4):502-5.

[3] AbdelRazek MA, Venna N, Stone JH. IgG4-related disease of the central and peripheral nervous systems. Lancet Neurol. 2018;17(2):183-92.

[4] Kamekura R, Takahashi H, Ichimiya S. New insights into IgG4-related disease: emerging new CD4+ T-cell subsets. Curr Opin Rheumatol. 2019;31(1):9-15.

Disclosure of Interests: None declared

DOI: 10.1136/annrheumdis-2021-eular.939 